Sandrine Skiba-Cassy, Marine Lansard, Stéphane Panserat and Françoise Médale Am J Physiol Regulatory Integrative Comp Physiol 297:1421-1429, 2009. First published Aug 26, 2009; doi:10.1152/ajpregu.00312.2009

You might find this additional information useful...

This article cites 54 articles, 14 of which you can access free at:

http://ajpregu.physiology.org/cgi/content/full/297/5/R1421\#BIBL

This article has been cited by 1 other HighWire hosted article:

Endocrine control of oleic acid and glucose metabolism in rainbow trout (Oncorhynchus mykiss) muscle cells in culture

J. Sanchez-Gurmaches, L. Cruz-Garcia, J. Gutierrez and I. Navarro

Am J Physiol Regulatory Integrative Comp Physiol, August 1, 2010; 299 (2): R562-R572.

[Abstract] [Full Text] [PDF]

Updated information and services including high-resolution figures, can be found at:

http://ajpregu.physiology.org/cgi/content/full/297/5/R1421

Additional material and information about American Journal of Physiology - Regulatory, Integrative and Comparative Physiology can be found at:

http://www.the-aps.org/publications/ajpregu

This information is current as of September 7, 2010 .

The American Journal of Physiology - Regulatory, Integrative and Comparative Physiology publishes original investigations that illuminate normal or abnormal regulation and integration of physiological mechanisms at all levels of biological organization, ranging from molecules to humans, including clinical investigations. It is published 12 times a year (monthly) by the American

Physiological Society, 9650 Rockville Pike, Bethesda MD 20814-3991. Copyright @ 2009 by the American Physiological Society. ISSN: 0363-6119, ESSN: 1522-1490. Visit our website at http://www.the-aps.org/. 


\title{
Rainbow trout genetically selected for greater muscle fat content display increased activation of liver TOR signaling and lipogenic gene expression
}

\author{
Sandrine Skiba-Cassy, Marine Lansard, Stéphane Panserat, and Françoise Médale \\ Unité Mixte de Recherches 1067 Nutrition Aquaculture and Génomique, Institut National de la Recherche Agronomique, Pôle \\ d'hydrobiologie, 64310 Saint Pée-sur-Nivelle, France
}

Submitted 8 June 2009; accepted in final form 19 August 2009

\begin{abstract}
Skiba-Cassy S, Lansard M, Panserat S, Médale F. Rainbow trout genetically selected for greater muscle fat content display increased activation of liver TOR signaling and lipogenic gene expression. Am J Physiol Regul Integr Comp Physiol 297: R1421-R1429, 2009. First published August 26, 2009; doi:10.1152/ajpregu.00312.2009.-Genetic selection is commonly used in farm animals to manage body fat content. In rainbow trout, divergent selection for low or high muscle fat content leads to differences in utilization of dietary energy sources between the fat muscle line (FL) and the lean muscle line (LL). To establish whether genetic selection on muscle fat content affects the hepatic insulin/nutrient signaling pathway, we analyzed this pathway and the expression of several metabolism-related target genes in the livers of the two divergent lines under fasting and then refeeding conditions. Whereas glycemia returned to basal level $24 \mathrm{~h}$ after refeeding in FL trout, it remained elevated in the LL trout. Target of rapamycin (TOR) protein was more abundant in the livers of FL trout than in LL trout, and refeeding activation of the hepatic TOR signaling pathway (TOR, S6K1, and S6) was therefore enhanced. Genes related to glycolysis (glucokinase and pyruvate kinase) and gluconeogenesis (glucose-6-phosphatase and phosphoenolpyruvate carboxykinase) were only slightly affected by refeeding and genetic selection. Refeeding stimulated expression of lipogenic genes and the sterolresponsive element binding protein (SREBP1), and expression of fatty acid synthase, glucose-6-phosphate dehydrogenase, and serine dehydratase was predominant in the livers of FL fish compared with LL fish. In agreement with recent findings linking TOR to lipogenesis control, we concluded that genetic selection for muscle fat content resulted in overactivation of the TOR signaling pathway-associated lipogenesis and probably also improved utilization of glucose.
\end{abstract}

metabolism; fattening; insulin-target of rapamycin signaling; messenger RNA levels

THE MANAGEMENT OF FAT DEPOSITION is a significant challenge for both human health and farm animal breeding. In humans, obesity expressed as overexpansion of the adipose tissue is often associated with the development of metabolic disorders, which is becoming increasingly prevalent worldwide and is projected to increase significantly over the next 10 years $(50)$. The management of fat deposition in farm animals, including fish, also has become highly significant, especially in terms of meat quality, since lipid storage in skeletal muscle affects the nutritional value and sensory properties of meat (49).

Genetic selection frequently has been used in farm animals to manage body fat content $(7 \mathrm{a}, 24)$ but rarely has been used in aquaculture. Two experimental lines of rainbow trout recently have been developed through divergent selection for low or high muscle fat content with the use of a nondestructive

Address for reprint requests and other correspondence: S. Skiba-Cassy, UMR 1067 Nutrition, Aquaculture \& Génomique, Institut National de la Recherche Agronomique, Pôle d'hydrobiologie, 64310 Saint-Pée-sur-Nivelle, France (e-mail: skiba@st-pee.inra.fr). measurement method on live fish (36). Genetic selection for high muscle fat content does not affect feed intake, and similar whole body fat contents were recorded in two lines of 80-g fish fed the same diet (20). Metabolic characterization of the lines led the authors to suggest that the lines presented differences in utilization of energy sources, with reduced hepatic fatty acid oxidation and enhanced glucose utilization in both the liver and the muscle of fish in the fat muscle line (FL) compared with the lean muscle line (LL) $(20,21)$. Since insulin controls glucose and lipid metabolism, we hypothesized that insulin pathways could have been affected by genetic selection for muscle fat content.

In addition to several other effects, insulin stimulates glucose and lipid storage as glycogen and triglycerides, respectively $(17,42)$, and also inhibits gluconeogenesis and fatty acid oxidation $(9,30)$. Insulin acts through a tyrosine kinase membrane receptor. When activated by insulin binding, tyrosine kinase recruits and phosphorylates intracellular substrates, known as insulin receptor substrates (IRS). Phosphorylated IRS are used as docking sites for proteins, which then transmit the insulin signal through several molecules (44). Thus, by successively activating the IRS-1, phosphatidylinositol 3-kinase (PI3K), and Akt (also known as protein kinase B), insulin was long thought to be the major regulator of hepatic gene expression, especially those genes related to intermediary metabolism. However, increasing evidence has emerged in the last few years that nutrients also are able to regulate hepatic gene expression in a transcriptional manner. Indeed, genes involved in glycolysis and lipogenesis are reciprocally regulated by glucose and fatty acids in the liver (7). Nutrients also may interact with insulin function. For example, excessive amino acid supply has detrimental effects on glucose homeostasis by promoting insulin resistance and increasing gluconeogenesis. This probably takes place through the activation of complex 1 of the mammalian target of rapamycin (mTORC1) (47). This complex is composed of mTOR, a member of the phosphoinositide 3-kinase-related kinase (PIKK) family (15), the regulatory associated protein of mTOR (Raptor) (18), and the G protein $\beta$-subunit-like protein $(\mathrm{G} \beta \mathrm{L})$, which plays a role in stabilizing mTOR-Raptor interactions (19). mTORC1 is regulated by both nutrients (i.e., amino acids) and growth factors (i.e., insulin) and controls cell growth and protein translation through the subsequent activation of p70 ribosomal S6 protein kinase 1 (S6K1) and ribosomal protein S6 (51). Recent findings also have indicated that activation of MTORC1 contributes to the regulation of fatty acid biosynthesis by favoring nuclear accumulation of the mature form of the sterol responsive element binding protein (SREBP1) and expression of SREBP target genes such as fatty acid synthase and ATP citrate lyase (35). 
In fish, insulin receptors are present in major insulin target tissues, including white muscle, liver, and adipose tissues (10, $25,31,32,34)$, and insulin is able to activate its signaling pathway in both rainbow trout muscle cells and hepatocytes $(34,37)$. To understand the differences that could explain the phenotypes of FL and LL fish, we investigated whether genetic selection of muscle fat content affected nutrient and insulin signaling pathways and metabolism-related gene expression by using rainbow trout from the above two lines resulting from the fourth generation of divergent selection. We examined plasma metabolite levels (glucose, triacylglycerol, and free fatty acids), insulin signaling, and mRNA expression of insulin target genes in both lines under short fasting (basal levels) and refeeding conditions. Attention was focused on genes related to glycolysis [glucokinase (GK) and pyruvate kinase (PK)], gluconeogenesis [glucose-6-phosphatase (G6Pase1 and G6Pase2) and phosphoenolpyruvate carboxykinase (PEPCK)], lipogenesis [fatty acid synthase (FAS), ATP-citrate lyase (ACLY), and glucose-6-phosphate dehydrogenase (G6PDH)], fatty acid oxidation [carnitine palmitoyl transferase 1 (CPT1a and CPT1b)], and amino acid degradation [serine dehydratase (SD)]. Transcript accumulation of the transcription factor SREBP1 also was evaluated. Analyses were conducted in the liver, which is considered the center of intermediary metabolism and the main site of lipogenesis in fish.

\section{MATERIALS AND METHODS}

Experimental and sampling procedure. The experiment was performed with two lines of rainbow trout, a lean muscle line (LL) and a fat muscle line (FL), obtained after four generations of divergent selection for high or low muscle fat content, evaluated using a nondestructive method (Distell Fish Fatmeter) as detailed by Quillet et al. (36). Triplicate groups of fish of both lines were reared in the Institut National de la Recherche Agronomique (INRA) experimental facilities (PEIMA, Sizun, Finistère, France) at a constant water temperature of $11.5 \pm 0.5^{\circ} \mathrm{C}$. Fish of each line were fed with an extruded diet manufactured in our own facilities (INRA, Donzaq, Landes, France). Ingredients and composition (Table 1) were similar to those of commercial diets currently used for rainbow trout farming. Feed

Table 1. Formula and analytical composition of diet

\begin{tabular}{lc}
\hline \hline \multicolumn{1}{c}{ Ingredients } & Content, g/kg \\
\hline Fish meal & 200.0 \\
Soybean meal & 200.0 \\
Corn gluten & 150.0 \\
Wheat gluten & 114.0 \\
Extruded whole wheat & 93.0 \\
Fish oil & 135.0 \\
Rapeseed oil & 29.0 \\
Linseed oil & 17.4 \\
Palm oil & 11.6 \\
Soya lecithin & 10.0 \\
CaHPO ${ }_{4} \cdot 2 \mathrm{H}_{2} \mathrm{O}(18 \% \mathrm{P})$ & 10.0 \\
Vitamin mix & 10.0 \\
Mineral mix & 10.0 \\
Binder & 10.0 \\
Analytical composition & Content \\
Dry matter, \% & 94.7 \\
Crude protein, \%DM & 46.3 \\
Crude fat, \%DM & 23.6 \\
Crude starch, \%DM & 9.7 \\
Gross energy, kJ/g DM & 24.9 \\
\hline
\end{tabular}

DM, dry matter. intake and weight gain were recorded during the 5 mo before the study, which was performed once fish reached the commercial size $(\sim 250 \mathrm{~g})$. Fish were left unfed for $48 \mathrm{~h}$ to obtain basal levels of plasma metabolites that are reached later in fish than in mammals due to slower intestinal transit and longer gastric emptying time at low temperatures compared with endothermic animals. Six fish were sampled from each tank. They were anesthetized with 2-phenoxyethanol at the recommended dose for surgical procedures $(0.2 \mathrm{ml} / \mathrm{l})$, individually weighed, and then killed by a sharp blow on the head. Livers and viscera were weighed to calculate the hepatosomatic index $[$ HSI $(\%)=100 \times($ liver weight/body weight $)]$ and the viscerosomatic index [VSI $(\%)=100 \times($ total viscera weight/body weight $)$. Three fish were frozen at $-20^{\circ} \mathrm{C}$ until analysis of whole body composition; the other three were sampled for blood and liver. The remaining fish were then hand fed a ration corresponding to $2 \%$ of the biomass. Three fish were sampled from each tank at 3 and $8 \mathrm{~h}$ after the meal. They were weighed, and their digestive tracts were observed to ensure that fish were in a postabsorptive state; the livers were excised, cut into two pieces, frozen in liquid nitrogen, and then stored at $-80^{\circ} \mathrm{C}$ until analysis. Further sampling was performed $24 \mathrm{~h}$ after the meal. After weighing, blood and livers were sampled as well as fillets from the left side of the fish, which were kept after trimming and skin removal as samples for analysis of lipid content. All experiments were carried out in accordance with legislation governing the ethical treatment of animals. Investigators were certified by the French Government to carry out animal experiments.

Plasma metabolite levels. Plasma glucose, triacylglycerol (TG), and free fatty acid (FFA) levels were measured with Glucose RTU (BioMerieux, Marcy l'Etoile, France), PAP 150 (Biomérieux, Marcy-l'étoile, France), and NEFA C kits (Wako Chemicals, Neuss, Germany), respectively, according to the recommendations of each manufacturer.

Protein extraction and Western blotting. Frozen livers (300 mg) from fasted and 3-h-refed trout were homogenized on ice with an Ultraturrax homogenizer in a buffer containing $150 \mathrm{mM}$ sodium chloride, 10 mM Tris , 1 mM EGTA, 1 mM EDTA (pH 7.4), 100 mM sodium fluoride, $4 \mathrm{mM}$ sodium pyrophosphate, $2 \mathrm{mM}$ sodium orthovanadate, $1 \%$ Triton X-100, 0.5\% Nonidet P-40-IGEPAL, and a protease inhibitor cocktail (Roche, Basel, Switzerland). Homogenates were centrifuged for $15 \mathrm{~min}$ at $12,000 \mathrm{~g}$ consecutively. The resulting supernatants were aliquoted and stored at $-80^{\circ} \mathrm{C}$. Protein concentrations were determined using the Bio-Rad protein assay kit (Hercules, $\mathrm{CA}$ ). Liver and cell lysates (20 $\mu \mathrm{g}$ of protein) were subjected to SDS-PAGE and Western blotting using the appropriate antibody. Anti-phospho Akt ( $\mathrm{Ser}^{473}$ ), anti-carboxyl terminal Akt, anti-phosphomTOR $\left(\mathrm{Ser}^{2448}\right)$, anti-mTOR, anti-phospho-S6K1 $\left(\mathrm{Thr}^{389}\right)$, antiS6K1, anti-phospho-S6 ( $\operatorname{Ser}^{235 / 236}$ ), and anti-S6 were purchased from Cell Signaling Technologies (Ozyme, Saint Quentin Yvelines, France). Specificity of the mammalian antibodies used was previously checked by alignment of amino acid sequences of peptides used to produce polyclonal antibodies with the corresponding trout sequences and comparative Western blots of trout and murine samples (37). After being washed, membranes were incubated with an IRDye infrared secondary antibody (LI-COR Biotechnology, Lincoln, NE). Bands were visualized by infrared fluorescence using the Odyssey imaging system (LI-COR Biotechnology) and quantified by Odyssey infrared imaging system software (version 1.2).

Gene expression analysis: real-time RT-PCR. Total RNA samples were extracted from $-80^{\circ} \mathrm{C}$ frozen livers of fasted fish and 8- and 24-h-refed fish by using Trizol reagent (Invitrogen, Carlsbad, CA) according to the manufacturer's recommendations. One microgram of the resulting total RNA was reverse transcribed into cDNA using the SuperScript III RNaseH- reverse transcriptase kit (Invitrogen) and random primers (Promega, Charbonnières, France) according to the instructions of each manufacturer. Target gene expression levels were determined by quantitative real-time RT-PCR using specific real-time PCR primers (Table 2). To avoid amplification of genomic DNA, 
Table 2. Primer sequences

\begin{tabular}{|c|c|c|}
\hline Gene & Primer Sequence & Amplicon Size, nt \\
\hline \multirow[t]{2}{*}{ EF1a } & F: 5'-TCCTCTTGGTCGTTTCGCTG-3' & \multirow[t]{2}{*}{159} \\
\hline & R: 5'-ACCCGAGGGACATCCTGTG-3' & \\
\hline \multirow[t]{2}{*}{ GK } & F: 5'-TGAAGGATCAGAGGTGGGTGATT-3' & \multirow[t]{2}{*}{253} \\
\hline & R: 5'-GAAGGTGAAACCCAGAGGAAGC-3' & \\
\hline \multirow[t]{2}{*}{ PK } & F: 5'-CCATCGTCGCGGTAACAAGA-3' & \multirow[t]{2}{*}{158} \\
\hline & R: 5'-ACATAGGAAAGGCCAGGGGC-3' & \\
\hline \multirow[t]{2}{*}{ PEPCK } & F: 5'-GTTGGTGCTAAAGGGCACAC-3' & \multirow[t]{2}{*}{149} \\
\hline & R: 5'-CCCGTCTTCTGATAAGTCCAA-3' & \\
\hline \multirow[t]{2}{*}{ G6Pase1 } & F: 5'-CTCAGTGGCGACAGAAAGG-3' & \multirow[t]{2}{*}{77} \\
\hline & R: 5'-TACACAGCAGCATCCAGAGC-3' & \\
\hline \multirow[t]{2}{*}{ G6Pase2 } & F: 5'-TAGCCATCATGCTGACCAAG-3' & \multirow[t]{2}{*}{82} \\
\hline & R: 5'-CAGAAGAACGCCCACAGAGT-3' & \\
\hline \multirow[t]{2}{*}{ SD } & F: 5'-CCCGTTTTTGGAGAGCATAG-3 & \multirow[t]{2}{*}{92} \\
\hline & R: 5'-TTTTGAATGAACCGGATGGT-3' & \\
\hline \multirow[t]{2}{*}{ FAS } & F: 5'-TGATCTGAAGGCCCGTGTCA-3' & \multirow[t]{2}{*}{161} \\
\hline & R: 5'-GGGTGACGTTGCCGTGGTAT-3' & \\
\hline \multirow[t]{2}{*}{ ACLY } & F: 5'-CTGAAGCCCAGACAAGGAAG-3' & \multirow[t]{2}{*}{149} \\
\hline & R: 5'-CAGATTGGAGGCCAAGATGT-3' & \\
\hline \multirow[t]{2}{*}{ G6PDH } & F: 5'-CTCATGGTCCTCAGGTTTG-3' & \multirow[t]{2}{*}{176} \\
\hline & R: 5'-AGAGAGCATCTGGAGCAAGT-3' & \\
\hline \multirow[t]{2}{*}{ CPT1a } & F: 5'-TCGATTTTCAAGGGTCTTCG-3' & \multirow[t]{2}{*}{166} \\
\hline & R: 5'-CACAACGATCAGCAAACTGG-3' & \\
\hline \multirow[t]{2}{*}{ CPT1b } & F: 5'-CCCTAAGCAAAAAGGGTCTTCA-3' & \multirow[t]{2}{*}{149} \\
\hline & R: 5'-CATGATGTCACTCCCGACAG-3' & \\
\hline \multirow[t]{2}{*}{ SREBP1 } & F: 5'-GACAAGGTGGTCCAGTTGCT-3' & \multirow[t]{2}{*}{59} \\
\hline & R: 5'-CACACGTTAGTCCGCATCAC-3 & \\
\hline
\end{tabular}

F, forward primer; R, reverse primer; nt, nucleotides. GenBank accession no. or Sigenae accession no. is as follows: elongation factor- $1 \alpha(\mathrm{EF} 1 \alpha)$, AF498320; glucokinase (GK), AF135403; pyruvate kinase (PK), AF246146; phosphoenolpyruvate carboxykinase (PEPCK), AF246149; glucose 6-phosphatase 1(G6Pase1), tcay0019b.d.18_3.1.s.om.8.1-1693; G6Pase2, AF120150; serine dehydratase (SD), tcay0007b.b.13_3.1.s.om.8; fatty acid synthase (FAS), tcab0001c.e.06_5.1.s.om.8; ATP-citrate lyase (ACLY), CA349411.1; glucose-6-phosphate dehydrogenase (G6PDH), CA351434; carnitine palmitoyltransferase 1a (CPT1a), AF 327058; CPT1b, AF606076.

primer pairs included one intron-spanning oligonucleotide when possible. The different PCR products were initially checked by sequencing to confirm the nature of the amplicon.

Quantitative RT-PCR was carried out on an iCycler iQ real-time PCR detection system (Bio-Rad) using iQ SYBR green supermix. Quantitative RT-PCR analyses were focused on several key enzymes of hepatic metabolism (34): 1) G6Pase and the mitochondrial isoform of phosphoenolpyruvate carboxykinase (mPEPCK), involved in gluconeogenesis; 2) GK and PK, which catalyze the phosphorylation of glucose and the conversion of phosphoenolpyruvate to pyruvate, the first and final steps in glycolysis, respectively $(45)$; 3) four enzymes involved in fatty acid metabolism, ACLY, FAS, G6PDH, and CPT1. ACLY and FAS successively allow the synthesis of fatty acids, primarily palmitate, by catalyzing the production of cytosolic acetyl$\mathrm{CoA}$ and oxaloacetate from citrate and then promoting the condensation of malonyl-CoA and acetyl-CoA (40). G6PDH, the committed step of the pentose phosphate shunt, catalyzes oxidation of the glucose coupled to the production of NADPH. The pentose phosphate pathway is a major source of reducing equivalents for biosynthesis reactions including fatty acid synthesis. CPT1 is responsible for the entry of fatty acids into mitochondria and is considered a rate-limiting enzyme of fatty acid $\beta$-oxidation (4). 4) We also examined mRNA expression of SD, which catalyzes the pyridoxal 50-phosphate-dependent deamination of serine and threonine in the liver to produce pyruvate and 2-oxobutyrate, respectively (13). According to the ancestral whole genome duplication that has occurred in the teleost lineage subsequent to its divergence from mammals, genes may be found in fish in multiple copies $(14,23)$. When different copies of a gene were known in rainbow trout (as for G6Pase and CPT1), gene expression analysis was performed on both copies. For the study of SREBP1 mRNA expression, we first characterized a partial cDNA encoding rainbow trout SREBP1 by using PCR primers (forward 5'-GCTGAGAGACAGCCTCAACC-3' and reverse 5'-AGGACGCATCTCACACTCCT-3' primers) designed from a Salmo salar expressed sequence tag (GenBank accession no. CA048941.1) presenting high homology with mammalian SREBP1 sequences. The resulting translated amplified rainbow trout sequence was compared with protein sequences present in the GenBank database using the BLAST network service at the National Center for Biotechnology Information (http://blast.ncbi.nlm.nih.gov/Blast.cgi) (1) and exhibited high sequence homology with mammalian SREBP1 $\left(P=3.10^{-23}\right.$ with human sequence). It was therefore considered to represent a partial rainbow trout SREBP1 cDNA sequence and was used to design PCR primers for quantitative RT-PCR (Table 2).

Elongation factor-1 $\alpha(E F 1 \alpha)$ was employed as a nonregulated reference gene, as previously used in rainbow trout $(26,34)$. No significant changes in EF1 $\alpha$ gene expression were observed in our investigations (data not shown). PCR was performed using $10 \mu \mathrm{l}$ of the diluted cDNA mixed with 5 pmol of each primer in a final volume of $25 \mu$ l. The PCR protocol was initiated at $95^{\circ} \mathrm{C}$ for $3 \mathrm{~min}$ for initial denaturation of the cDNA and hot-start iTaq TM DNA polymerase activation and continued with a two-step amplification program (20 s at $95^{\circ} \mathrm{C}$ followed by $30 \mathrm{~s}$ at specific primer hybridization temperature) repeated 40 times. Melting curves were systematically monitored (temperature gradient at $0.5^{\circ} \mathrm{C} / 10 \mathrm{~s}$ from 55 to $94^{\circ} \mathrm{C}$ ) at the end of the last amplification cycle to confirm the specificity of the amplification reaction. Each PCR run included replicate samples (duplicate of reverse transcription and PCR amplification, respectively) and negative controls (reverse transcriptase and RNA-free samples, respectively). Relative quantification of target gene expression was performed using the mathematical model described by Pfaffl (33). The relative expression ratio $(\mathrm{R})$ of the target gene was calculated based on the real-time PCR efficiency (E) and the threshold cycle (CT) deviation $(\Delta \mathrm{CT})$ of the unknown sample vs. that of a control sample made of a mix of all samples and is expressed compared with the EF1 $\alpha$ reference gene:

$$
\mathrm{R}=\frac{\left.\left[\left(\mathrm{E}_{\text {target gene }}\right) \Delta \mathrm{CT}_{\text {target gene (control - sample }}\right)\right]}{\left[\left(\mathrm{E}_{\mathrm{EF1} 1 \alpha}\right) \Delta \mathrm{CT} \mathrm{T}_{\mathrm{EF} 1 \alpha(\text { control - sample })}\right]}
$$

PCR efficiency (E) was measured as the slope of a standard curve using serial dilution of cDNA, and all values were above 1.9.

Statistical analysis. Results of growth, nutrient utilization, and body composition are means $\pm \mathrm{SE}(n=3$ tanks) and were analyzed using one-way ANOVA to assess the differences between lines. Results from plasma metabolite levels $(n=9)$ and gene expression $(n=6)$ are means \pm SE and were analyzed using two-way ANOVA to assess differences between lines, sampling time, and interactions. When an interaction was significant, means were compared using the Newman-Keuls multiple comparison test. Protein phosphorylation levels are means $\pm \mathrm{SE}(n=6)$ and were analyzed using MannWhitney nonparametric tests. For all statistical analyses, the level of significance was set at $P<0.05$.

\section{RESULTS}

Weight gain, whole body fat content, and tissue composition. Trout from the lean muscle line (LL) had higher body weights $\left(P<10^{-4}\right)$ than fish from the FL at the time of the study, despite having a slightly lower feed intake $(6.4 \mathrm{~g}$ dry matter $\cdot \mathrm{kg}$ body $\mathrm{wt}^{-1}$. day for $\mathrm{LL}$ and $6.85 \mathrm{~g}$ dry matter $\cdot \mathrm{kg}$ body $\mathrm{wt}^{-1}$. day for FL) during the 5 mo before the study (Table 3 ). Feed efficiency was thus better in LL than in FL fish. Although daily fat gain was increased in FL compared with LL fish $(P=$ $0.017)$, the nitrogen gain was similar in the two lines $(P=$ 0.57). As expected, as the target of the genetic selection, 
Table 3. Main features of rainbow trout from $F L$ and $L L$

\begin{tabular}{lccl}
\hline \hline & $\mathrm{FL}$ & $\mathrm{LL}$ & $P$ Value \\
\hline Individual mean body weight, g) & $236.7 \pm 6.5 \dagger$ & $277.7 \pm 1.2^{*}$ & $<10^{-4}$ \\
Daily growth coefficient, \% & $1.45 \pm 0.01 \dagger$ & $1.64 \pm 0.01 *$ & 0.0003 \\
Feed efficiency & $1.15 \pm 0.01 \dagger$ & $1.28 \pm 0.01^{*}$ & 0.002 \\
Nitrogen gain, $\mathrm{mg} \cdot \mathrm{kg} \mathrm{BW}^{-1} \cdot$ day & $186.8 \pm 7.1$ & $192.6 \pm 6.2$ & 0.57 \\
Fat gain, $\mathrm{g} \cdot \mathrm{kg} \mathrm{BW} \mathbf{B ~}^{-1} \cdot \mathrm{day}$ & $1.27 \pm 0.04 *$ & $1.03 \pm 0.04 \dagger$ & 0.017 \\
Digestive tract/whole body, \% & $10.0 \pm 0.2$ & $10.7 \pm 0.2$ & 0.48 \\
Muscle fat content, \%WW & $10.0 \pm 0.4^{*}$ & $5.0 \pm 0.3 \dagger$ & $<10^{-4}$ \\
Whole body fat content, \%WW & $15.1 \pm 0.3^{*}$ & $12.5 \pm 0.4 \dagger$ & 0.005 \\
Whole body protein content, \%WW & $15.0 \pm 0.3$ & $15.4 \pm 0.4$ & 0.47 \\
\hline
\end{tabular}

Values are means $\pm \mathrm{SE}(n=3)$. FL and LL, fat and lean muscle lines of fish; WW, wet weight. $* \dagger P<0.05$, means with different symbols are significantly different from each other.

muscle fat content was twice as high in the FL than in the LL fish, whereas whole body fat content was higher in FL fish $(+20.8 \%)$. Muscle fat stores represented 33.2 and $19.8 \%$ of whole body fat stores in FL and LL fish, respectively. The percentage of digestive tract including abdominal adipose tissue was not significantly different between lines $(P=0.48)$.

Plasma metabolite levels. The results for plasma metabolites measured on fasted fish and 3, 8, and $24 \mathrm{~h}$ after refeeding are presented in Fig. 1. Refeeding induced a weak but significant increase in plasma glucose levels in both fish lines, reaching $6.19 \pm 0.37$ and $6.37 \pm 0.41 \mathrm{mM}$ for FL and LL fish, respectively, $8 \mathrm{~h}$ after refeeding. As indicated by the significant interaction between sampling time and line, plasma glucose levels remained elevated in the LL fish $24 \mathrm{~h}$ after refeeding, whereas it decreased significantly between 8 and $24 \mathrm{~h}$ in the FL fish. Plasma FFA levels were not significantly different between lines over the refeeding period. Plasma FFA levels decreased significantly 3 and $8 \mathrm{~h}$ after refeeding and then returned to fasting values $24 \mathrm{~h}$ after refeeding. Compared with the LL fish, FL fish presented significantly higher TG plasma levels. On the other hand, the evolution of TG plasma levels was similar after refeeding for both fish lines, increasing gradually between fasted and 24-h-refed fish from $2.14 \pm 0.10$ and $1.93 \pm 0.13 \mathrm{mM}$ to $4.31 \pm 0.38$ and $3.48 \pm 0.41 \mathrm{mM}$ for FL and LL fish, respectively.

Akt/TOR signaling pathway. Using Western blot analyses, we investigated the effects of refeeding on Akt/TOR signaling pathways in FL and LL fish by comparing fasted and 3-h-refed fish. As shown in Fig. 2, refeeding resulted in enhanced phosphorylation of Akt, TOR, S6K1, and S6 proteins. To compare the levels of activation of the different signaling molecules following refeeding, we loaded liver protein samples from 3-h-refed fish from both lines on the same gel and subjected them to Western blot analyses. Figure 3 represents Western blot images of phosphorylated (P-) and total forms of Akt, TOR, S6K1, and S6. A ratio between the phosphorylated and total forms of the protein was calculated for each protein. Analysis of Akt data indicated that levels of P-Akt and Akt were not significantly different between FL and LL fish. Although similar quantities of proteins $(20 \mu \mathrm{g})$ were loaded on the gels, TOR and P-TOR protein levels were both significantly more highly increased in the FL compared with the LL fish. Consequently, there was no difference between lines when the ratio between P-mTOR and total mTOR was considered. S6K1 and S6 protein presented similar patterns. Levels of phosphorylated forms of S6K1 and S6 were enhanced in the FL fish. Since both lines presented equal abundance of total S6K1 and S6, the phosphorylated-to-total protein ratio was increased in the FL fish.

Messenger RNA levels of target genes. To compare the effects of refeeding on the hepatic intermediary metabolismrelated gene expression in both lines, we performed quantitative RT-PCR on several genes belonging to glucose, lipid, and energy metabolism. Messenger RNA levels of GK, PK, G6Pase1 and G6Pase2, PEPCK, SD, ACLY, FAS, G6PDH, CPT1a and CPT1b, and SREBP1 were measured as indexes of gene expression in fasted fish as well as 8 and $24 \mathrm{~h}$ after refeeding. Since samples collected $8 \mathrm{~h}$ after refeeding exhibited mRNA levels of the different genes that were not significantly different from those measured in fasting fish (data not shown), the results summarized in Fig. 4 correspond to fasted and 24-h-refed nutritional status. GK mRNA levels increased significantly between fasted and 24-h-refed fish in both lines. Expression of PK mRNA was similar between lines and remained unchanged between fasted and refed fish. Over the three gluconeogenic genes explored (G6Pase1, G6Pase2, and
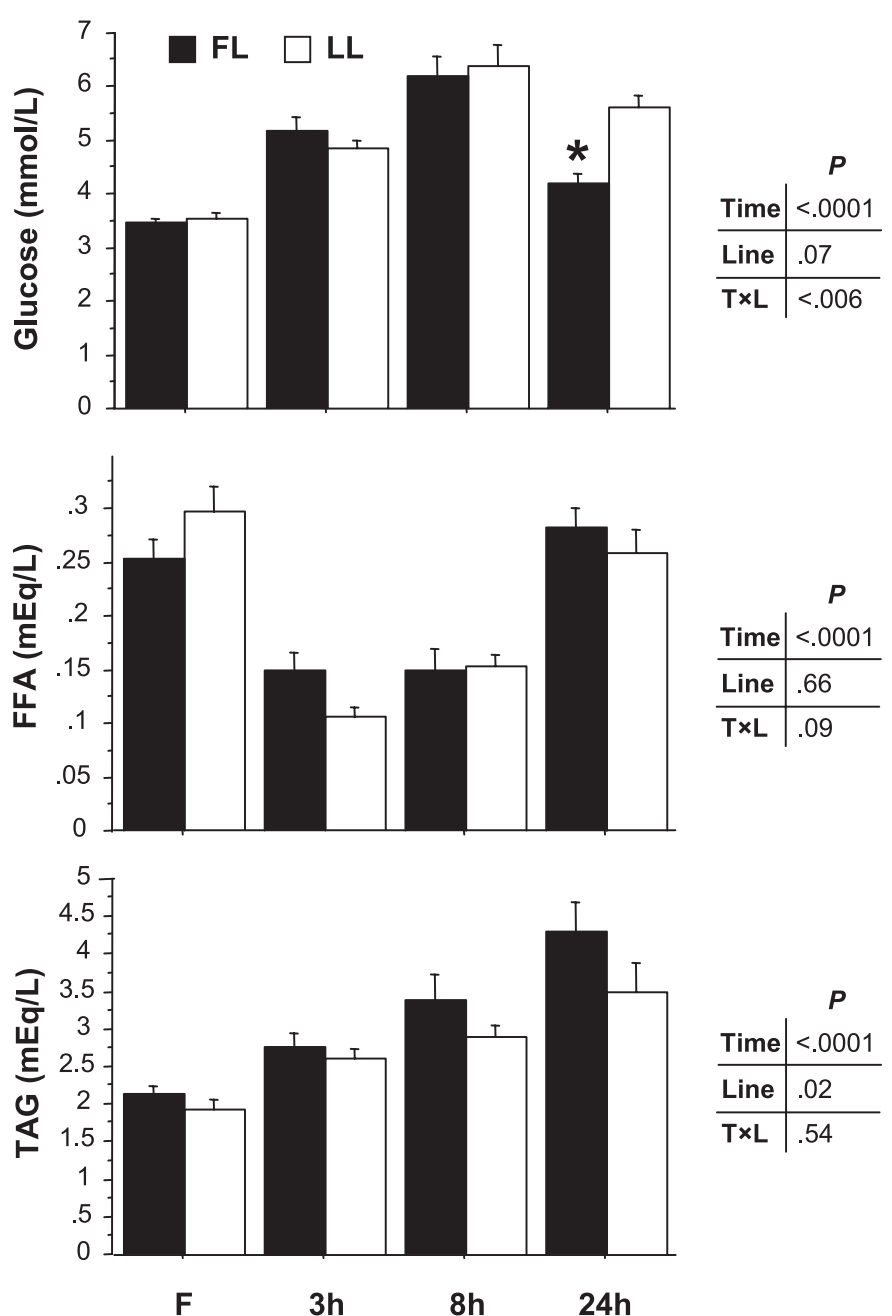

Fig. 1. Plasma levels of glucose, free fatty acids (FFA), and triacylglycerol (TAG) in fish from the fat (FL) and the lean lines (LL) 3, 8, and $24 \mathrm{~h}$ after refeeding ( 0 corresponds to fasted fish). Data are means \pm SE of 9 samples. $P$ values for the time, line, and interaction effects are indicated at right. $* P<$ 0.05 , significant difference in plasma glucose levels between FL and LL $24 \mathrm{~h}$ after refeeding. 


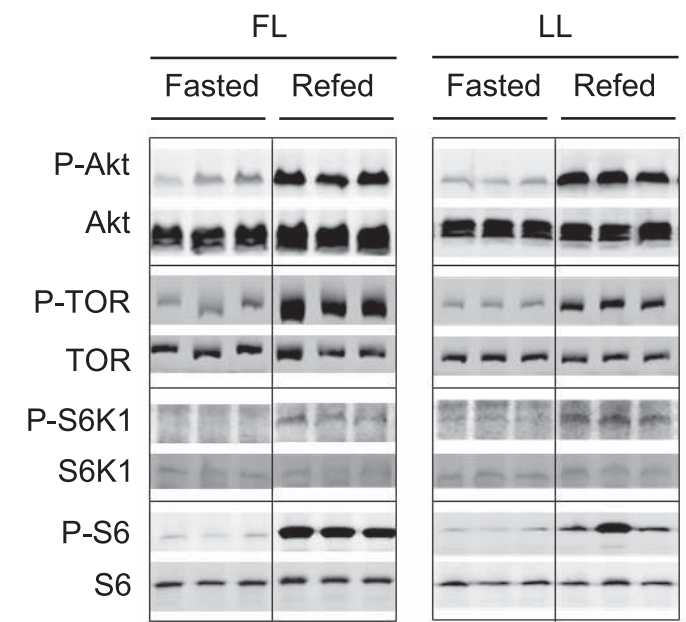

Fig. 2. Western blot analysis of Akt, target of rapamycin (TOR), p70 ribosomal S6 protein kinase 1 (S6K1), and S6 protein phosphorylation in fasted and 3-h-refed rainbow trout livers from FL and LL. P-Akt, P-TOR, P-S6K1, and P-S6, phosphorylated forms of Akt, TOR, S6K1, and S6, respectively. Twenty micrograms of total protein per lane were loaded on the gel. A representative blot is shown. Western blots were performed on 6 individual samples that provided similar results.

PEPCK), the first isoform of G6Pase was the only gene subjected to regulation of refeeding, since it decreased $24 \mathrm{~h}$ after refeeding. On investigating the regulation of expression of lipid metabolism-related genes, we found that mRNA expression of genes encoding FAS and G6PDH was upregulated $24 \mathrm{~h}$ after refeeding in both lines. Messenger RNA expression of the ACLY gene tended to increase in 24-h-refed fish, but the increase did not reach statistical significance $(P=0.07)$. On the other hand, we observed that expression of ACLY, FAS, and G6PDH mRNA was on the whole significantly higher in FL fish compared with LL fish, with 1.6-fold higher levels of ACLY mRNA in fasted and 24-h-refed FL fish, 7.3- and 3.7-fold higher levels of FAS mRNA in fasted and 24-h-refed FL fish, respectively, and 2.6- and 2.5-fold higher levels of G6PDH mRNA in fasted and 24-h-refed FL fish, respectively. Messenger RNA levels of SREBP1 were subjected to considerable differences between fasted and 24-h-refed fish, with a 5.7- and 2.7-fold increase in FL and LL fish, respectively. However, no significant difference was noted between lines. As regards the mRNA expression of CPT1, we found that both isoforms were unaffected by refeeding. On the other hand, the LL fish presented higher expression of the b isoform of CPT1, whereas the a isoform was equally expressed in both lines. Finally, we investigated mRNA expression of SD as a potential source of pyruvate for further gluconeogenesis or lipogenesis and recorded lower levels of expression in LL fish. Expression of SD mRNA was not affected by nutritional status.

\section{DISCUSSION}

The aim of the present study to achieve greater understanding of the molecular mechanisms leading to muscle fat accumulation by comparing fish lines selected for low and high muscle fat content. Our study focused on the insulin/nutrient signaling pathways as a major regulator of metabolism and examined the expression of several metabolism-related target genes.
Lines issued from the third generation of selection presented similar whole body fat contents but different muscle fat contents (20). The continuation of the selection procedure (fourth generation of selection) has increased the divergence in muscle fat levels that led to enhanced whole body fat content. The absence of difference in abdominal adipose tissue, which is the predominant site of fat storage in salmonids, distinguishes this model from other farm animal models obtained through genetic selection, which generally resulted in overall increase in body fat over the different body compartments $(3,38)$. In the present study, increased muscle adiposity in FF fish was not due to higher growth rate or better feed efficiency. In addition, the genetic selection has increased fat gain without a concomitant decrease in nitrogen gain.

Carnivorous fish such as rainbow trout are characterized by a limited ability to use dietary carbohydrates efficiently (48) and are thus considered to be "glucose intolerant" (10a, 24a). Oral or intravenous administration of glucose and a carbohydrate-rich diet result in persistent hyperglycemia in various fish species, including the rainbow trout $(5,7,22 \mathrm{a}, 26 \mathrm{a}, 31)$. Comparison of plasma glucose levels of the two lines revealed that fish from the FL seemed to have a better ability to manage postprandial plasma glucose levels than LL fish. Glycemia remained significantly elevated in LL fish $24 \mathrm{~h}$ after refeeding, whereas it decreased in FL fish to reach levels similar to those measured in 48-h-fasted fish. This result reinforces the hypothesis that divergent selection for muscle fat content in trout has modified the mechanisms of fuel utilization, especially the ability of the fish to use glucose.

Glucose homeostasis results from a balance between glucose utilization through glycolysis and glucose production through gluconeogenesis and glycogenolysis. Investigation of GK and PK gene expression suggested that the glycolytic pathway was not differentially regulated between lines. This should be confirmed by analyzing the whole glycolytic flux at both molecular and cellular levels. Impaired postprandial inhibition of hepatic endogenous production of glucose is a metabolic feature of rainbow trout $(27-29,46)$. This study again confirmed that gluconeogenesis is only slightly affected by refeeding in rainbow trout, since of the three gluconeogenic genes examined (the 2 isoforms of G6Pase and PEPCK), only the first isoform of G6Pase was downregulated $24 \mathrm{~h}$ after refeeding. Analysis of the two isoforms of G6Pase confirmed that, in fish, different copies of a gene resulting from the genome duplication event may have evolved separately and acquired different patterns of expression, as previously reported for pro-opiomelanocortin (22). Regarding these enzymes, FL and LL fish responded similarly to refeeding, suggesting that endogenous production of glucose was not responsible for the persistence of increased plasma glucose over $24 \mathrm{~h}$ after refeeding in the LL fish.

The purpose of plasma glucose is mainly as fuel through the glycolytic pathway or transformation (among others) into lipids and then storage in adipose tissues and, to a lesser extent, skeletal muscle. Analysis of ACLY, FAS, and G6PDH gene expression confirmed that, as expected, refeeding stimulated lipogenic gene expression. In mammals, FAS expression is regulated by insulin, and this action is mediated by the PI3K/ Akt signaling pathway (43). The concomitant regulation of FAS and hepatic activation of Akt under refeeding conditions in both lines suggests insulin regulation similar to that de- 
Fig. 3. Western blot analysis of Akt, TOR, S6K1, and S6 protein phosphorylation in 3-h-refed rainbow trout livers from FL and LL. Twenty micrograms of total protein per lane were loaded on the gel. A representative blot is shown. Western blots were performed on 6 individual samples that provided similar results. Graphs represent the ratio between the phosphorylated protein and the total amount of the targeted protein. Protein phosphorylation data are means $\pm \operatorname{SE}(n=6)$ and were analyzed using Mann-Whitney nonparametric tests. $* P<0.05$, significant difference in the phosphorylated (phospho)/total protein ratio between LL and FL fish. $\S P<0.05$, significant difference in the phosphorylated protein level or the total protein level between LL and FL fish.
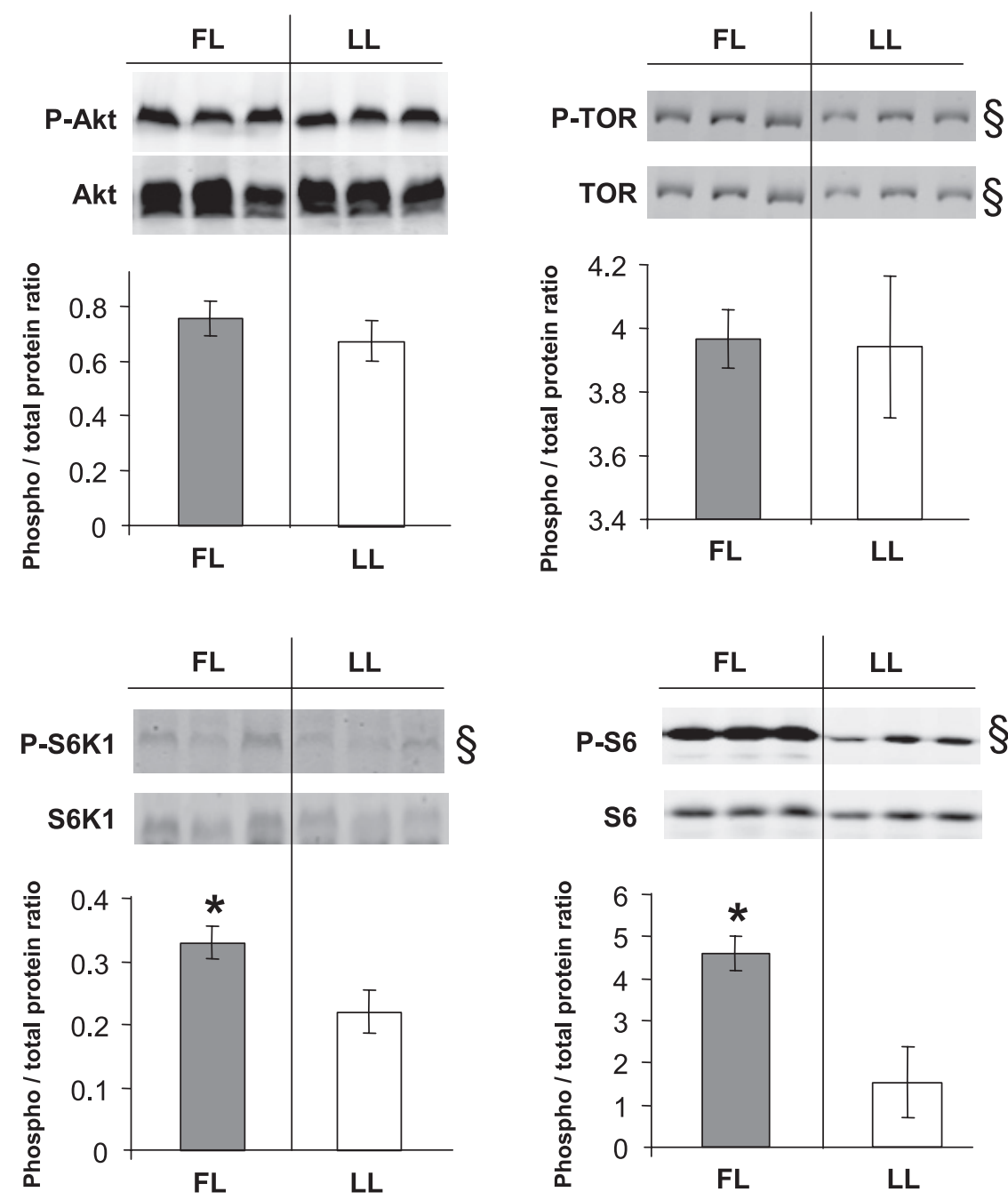

scribed in mammals. Interestingly, whereas both FL and LL fish responded to refeeding, expression of ACLY, FAS, and G6PDH was significantly higher in the FL than in the LL fish, indicating that lipogenesis was enhanced in the FL fish. This was also corroborated by the plasma TG levels that were always higher in the FL than in the LL fish under both fasting and refeeding conditions. The greater hepatic expression of SD in the FL fish also supported the hypothesis of enhanced lipogenesis in fish selected for high muscle fat content. Indeed, SD catalyzes the pyridoxal phosphate (PLP)-dependent deamination of serine to produce pyruvate. In mammals, SD is involved in the regulation of liver gluconeogenesis from serine in different dietary, hormonal, and developmental states by providing pyruvate (41). In the case of rainbow trout, pyruvate originating from SD activity might be directed through lipid synthesis and thus contribute to the enhanced lipogenesis of FL fish. Enhanced lipogenesis might therefore explain the better utilization of plasma glucose levels in FL fish and their increased adiposity compared with LL fish. Since a study by Corraze et al. (6) demonstrated that neosynthesized lipids in rainbow trout were preferentially incorporated in the muscle rather than in visceral adipose tissue, this suggests that enhanced lipogenesis has a key role in the phenotype of the FL fish.
Control of lipogenesis is mainly mediated by insulin and nutrients. Porstmann et al. (35) recently demonstrated that fatty acid biosynthesis was regulated by mTORC1 under the transcriptional control of SREBP1, a mediator of the expression of lipogenic enzymes. We therefore hypothesized that activation of the insulin/TOR signaling pathway might be different between the two fish lines. Using Western blot analysis of TOR phosphorylation as well as S6K1 and S6 phosphorylation (2 successive targets of TOR) as indicators for TOR activity, we demonstrated that TOR activity is enhanced in the livers of refed FL fish compared with LL refed fish. The increased TOR activity seemed to result rather from increased abundance of TOR protein, since the ability of insulin to phosphorylate TOR was similar in the two lines. These results thus led us to hypothesize that genetic selection of rainbow trout on muscle fat content had favored the mTOR pathway and, consequently, lipogenesis by enhancing the abundance of TOR protein. This study therefore confirms previous findings linking mTOR pathway to lipogenesis in the liver of obese rats (16), and the findings are in agreement with the recent publication by Porstmann et al. (35). In mammals, SREBP1 is essential for the transcriptional control of genes encoding enzymes of lipid biosynthesis such as FAS and ACLY and is considered to be the link between TOR and lipogenic gene expression control. 

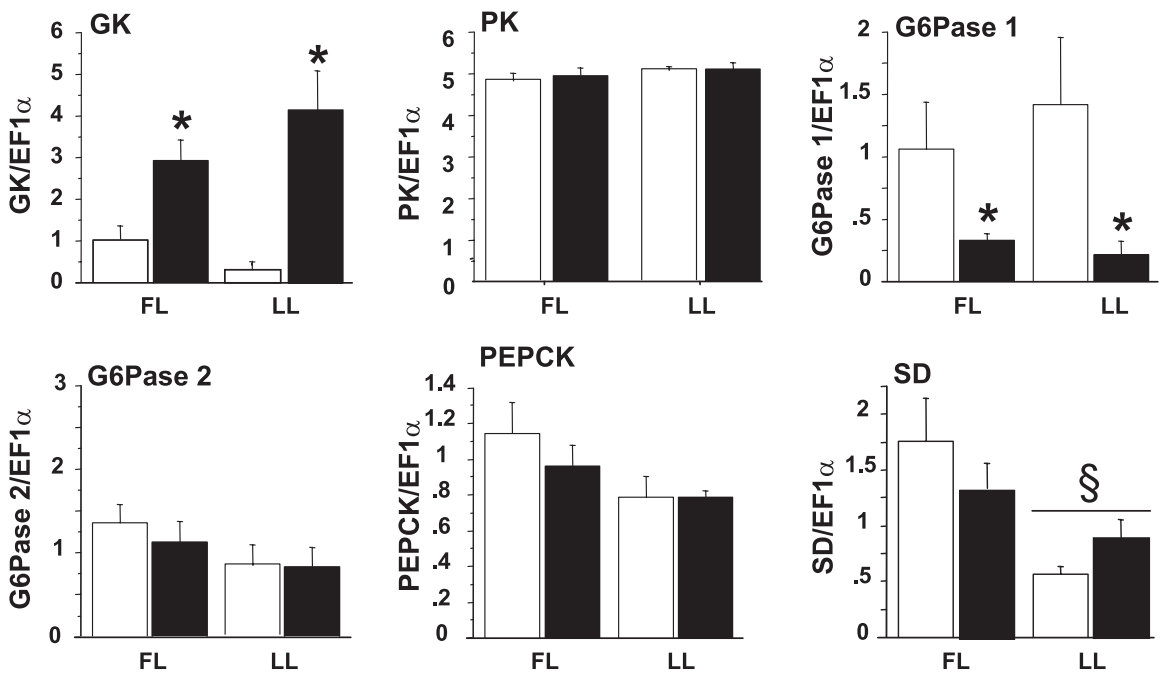

Fig. 4. Gene expression of selected enzymes in the livers of fasted (open bars) and 24-h-refed (filled bars) rainbow trout from FL and LL. Glucokinase (GK), pyruvate kinase $(\mathrm{PK})$, glucose-6-phosphatase isoforms 1 and 2 (G6Pase1 and G6Pase2), phosphoenolpyruvate carboxykinase (PEPCK), serine dehydratase (SD), ATP-citrate lyase (ACLY), fatty acid synthase (FAS), glucose-6-phosphate dehydrogenase (G6PDH), carni-
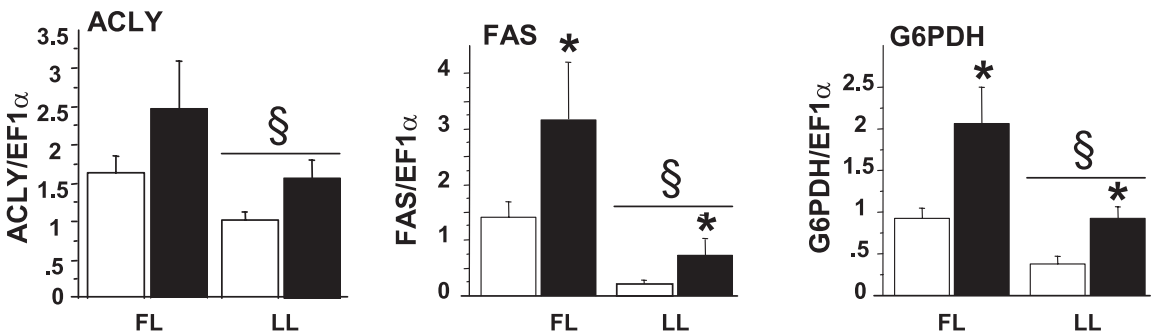
tine palmitoyltransferase 1 (CPT1a and CPT1b), and sterol responsive element binding protein (SREBP1) mRNA levels were evaluated using real-time RT-PCR. Expression values are normalized with elongation factor- $1 \alpha(\mathrm{EF} 1 \alpha)$-expressed transcripts. Results are means $+\mathrm{SE}(n=6)$ and were analyzed using 2-way ANOVA followed by the Student-Newman-Keuls test for multiple comparison. ${ }^{*} P<0.05$, significant effect of refeeding. $\S P<0.05$, significant effect of line.
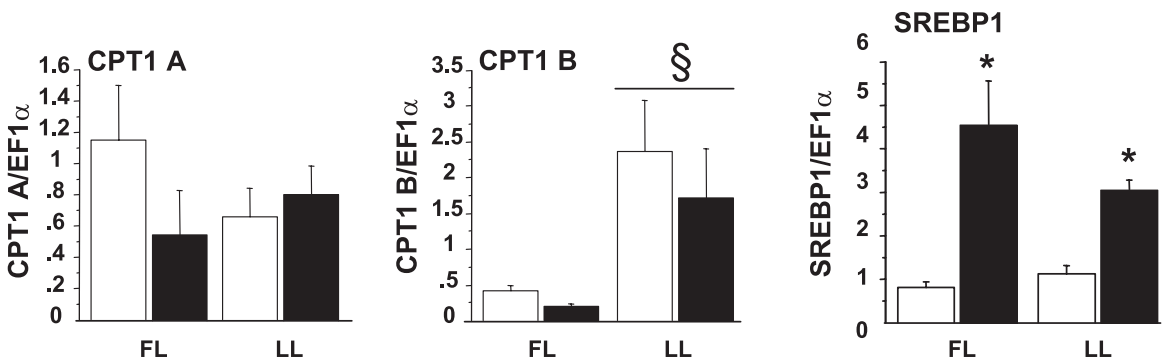

Three members of the SREBP family have been described in mammals, i.e., SREBP1a, SREBP1c, and SREBP2. SREBP1a and SREBP1c are encoded by a single gene through the use of alternative transcription start sites and differ by their first exon (12). In mammals, SREBP1c is mainly expressed in the liver, white adipose tissue, adrenal glands, and brain, whereas SREBP1a is mainly expressed in tissues with a high capacity for cell proliferation such as the spleen and intestines (39). Since SREBP1 primers were designed from a newly partial rainbow trout SREBP1 cDNA sequence located in the $3^{\prime}$ end of the gene, primers consequently targeted shared regions of SREBP1a and SREBP1c. The upregulation of SREBP gene expression in rainbow trout caused by refeeding is therefore totally consistent with the mammalian regulation of SREBP1c, because SREBP1c is the only SREBP isoform whose expression is depressed during fasting and markedly increased after refeeding (11). The higher levels of expression of lipogenic genes observed in FL compared with LL fish were not accompanied by enhanced expression of SREBP1, as previously demonstrated for two divergent fat and lean chicken lines (2). Nevertheless, the increase in SREBP1 transcript levels between fasted and 24-h-refed fish was clearly greater in FL than in LL fish, which may signify stronger postprandial stimulation of lipogenesis in FL than in LL fish. This hypothesis needs to be confirmed by in vivo measurement of lipogenesis from labeled substrates. However, the regulation of SREBP1 also may occur at posttranslational level via proteolytic cleavage. Actually, the SREBP1c precursor interacts with the SREBP cleavage-activating protein (SCAP) to form a complex retained in the endoplasmic reticulum (ER) by its interaction with the integral membrane protein termed insulin-induced gene-1 (Insig). Under appropriate signals (insulin, ER stress), the SREBP1c-SCAP complex migrates to the Golgi apparatus, where SREBP1c undergoes two sequential proteolytic cleavages by site 1 protease (S1P) and site 2 protease (S2P), yielding the mature active form of SREBP1c, which is translocated into the nucleus and binds to specific response elements on the promoter of its targets genes (for review, see Ref. 8).

Finally, we also demonstrated that CPT1b mRNA was less represented in the livers of FL than LL fish. However, since the a isoform was similarly expressed in both lines and CPT1 activity was not measured in the present study, we cannot clearly conclude that LL fish have an enhanced ability to use fatty acids as an energy source, although our findings partly 
confirm those obtained from fish originating from the previous generation of selection (20).

\section{Perspective and Significance}

The present study indicates that genetic selection of rainbow trout for muscle fat content resulted in fish with improved ability to use plasma glucose, potentially due to enhanced lipogenesis driven by an augmented TOR signaling pathway. Since neosynthesized lipids are targeted in preference to the skeletal muscle in rainbow trout, our combined findings provide a potential explanation of the mechanisms that lead to enhancement of fat accumulation in the muscle of the fat line. Our results confirm the hypothesis linking TOR to control of fat metabolism and expand it to a nonmammalian species. However, it remains to be determined how enhanced TOR activity leads to increased lipogenic gene expression and what the role of SREBP1c may be in the underlying molecular mechanisms. The differential activation of the TOR signaling pathway and the divergent fat accumulation the two divergent lines of rainbow trout selected for muscle fat content show this to be a relevant model to investigate the mechanisms linking the TOR pathway to lipogenesis. Since the TOR signaling pathway is regulated by cellular energy status, through negative regulation by AMP-activated protein kinase as well as by availability of amino acids, fat and lean muscle rainbow trout lines also will be valuable to investigate how to control fat synthesis through nutritional control of the TOR pathway.

\section{ACKNOWLEDGMENTS}

We thank M. J. Borthaire, E. Plagnes-Juan, C. Vachot, and F. A. Poujade for technical assistance, as well as the technical staff at the Institut National de la Recherche Agronomique (INRA) experimental facilities of Pisciculture Expérimentale INRA des Monts d'Arrée (Drennec, Sizun, France).

\section{REFERENCES}

1. Altschul SF, Gish W, Miller W, Myers EW, Lipman DJ. Basic local alignment search tool. J Mol Biol 215: 403-410, 1990.

2. Assaf S, Lagarrigue S, Daval S, Sansom M, Leclercq B, Michel J, Pitel F, Alizadeh M, Vignal A, Douaire M. Genetic linkage and expression analysis of SREBP and lipogenic genes in fat and lean chicken. Comp Biochem Physiol B 137: 433-441, 2004.

3. Baeza E, de Carville H, Salichon MR, Marche G, Leclercq B. Effects of selection, over three and four generations, on meat yield and fatness in Muscovy ducks. Br Poult Sci 38: 359-365, 1997.

4. Bartlett K, Eaton S. Intermediates of mitochondrial beta-oxidation. Biochem Soc Trans 22: 432-436, 1994.

5. Bergot F. Effects of dietary carbohydrates and of their mode of distribution on glycaemia in rainbow trout (Salmo gairdneri richardson). Comp Biochem Physiol A 64: 543-547, 1979.

6. Corraze G, Kaushik S. Les lipides des poissons marins et d'eau douce. Oléagineux Corps Gras Lipides 6: 111-115, 1999.

6a.del sol Novoa M, Capilla E, Rojas P, Baro J, Gutierrez J, Navarro I. Glucagon and insulin response to dietary carbohydrate in rainbow trout (Oncorhynchus mykiss). Gen Comp Endocrinol 139: 48-54, 2004.

7. Dentin R, Denechaud PD, Benhamed F, Girard J, Postic C. Hepatic gene regulation by glucose and polyunsaturated fatty acids: a role for ChREBP. J Nutr 136: 1145-1149, 2006.

7a.Eisen EJ. Selection experiments for body composition in mice and rats: a review. Livest Prod Sci 23: 17-32, 1989.

8. Ferre P, Foufelle F. SREBP-1c transcription factor and lipid homeostasis: clinical perspective. Horm Res 68: 72-82, 2007.

9. Granner D, Pilkis S. The genes of hepatic glucose metabolism. J Biol Chem 265: 10173-10176, 1990.

10. Gutierrez J, Asgard T, Fabbri E, Plisetskaya EM. Insulin-receptor binding in skeletal-muscle of trout. Fish Physiol Biochem 9: 351-360, 1991.
10a.Hemre GI, Mommsen TP, Krogdahl A. Carbohydrates in fish nutrition: effects on growth, glucose metabolism and hepatic enzymes. Aquac Nutr 8: 175-194, 2002.

11. Horton JD, Bashmakov Y, Shimomura I, Shimano H. Regulation of sterol regulatory element binding proteins in livers of fasted and refed mice. Proc Natl Acad Sci USA 95: 5987-5992, 1998.

12. Hua X, Wu J, Goldstein JL, Brown MS, Hobbs HH. Structure of the human gene encoding sterol regulatory element binding protein-1 (SREBF1) and localization of SREBF1 and SREBF2 to chromosomes 17p11.2 and 22q13. Genomics 25: 667-673, 1995.

13. Ishikawa E, Ninagawa T, Suda M. Hormonal and dietary control of serine dehydratase in rat liver. J Biochem 57: 506-513, 1965.

14. Jaillon O, Aury JM, Brunet F, Petit JL, Stange-Thomann N, Mauceli E, Bouneau L, Fischer C, Ozouf-Costaz C, Bernot A, Nicaud S, Jaffe D, Fisher S, Lutfalla G, Dossat C, Segurens B, Dasilva C, Salanoubat M, Levy M, Boudet N, Castellano S, Anthouard V, Jubin C, Castelli V, Katinka M, Vacherie B, Biemont C, Skalli Z, Cattolico L, Poulain J, De Berardinis V, Cruaud C, Duprat S, Brottier P, Coutanceau JP, Gouzy J, Parra G, Lardier G, Chapple C, McKernan KJ, McEwan P, Bosak S, Kellis M, Volff JN, Guigo R, Zody MC, Mesirov J, LindbladToh K, Birren B, Nusbaum C, Kahn D, Robinson-Rechavi M, Laudet V, Schachter V, Quetier F, Saurin W, Scarpelli C, Wincker P, Lander ES, Weissenbach J, Roest Crollius H. Genome duplication in the teleost fish Tetraodon nigroviridis reveals the early vertebrate proto-karyotype. Nature 431: 946-957, 2004.

15. Keith CT, Schreiber SL. PIK-related kinases: DNA repair, recombination, and cell cycle checkpoints. Science 270: 50-51, 1995.

16. Khamzina L, Veilleux A, Bergeron S, Marette A. Increased activation of the mammalian target of rapamycin pathway in liver and skeletal muscle of obese rats: possible involvement in obesity-linked insulin resistance. Endocrinology 146: 1473-1481, 2005.

17. Khan AH, Pessin JE. Insulin regulation of glucose uptake: a complex interplay of intracellular signalling pathways. Diabetologia 45: 14751483, 2002.

18. Kim DH, Sarbassov DD, Ali SM, King JE, Latek RR, ErdjumentBromage H, Tempst P, Sabatini DM. mTOR interacts with raptor to form a nutrient-sensitive complex that signals to the cell growth machinery. Cell 110: 163-175, 2002.

19. Kim DH, Sarbassov DD, Ali SM, Latek RR, Guntur KVP, ErdjumentBromage H, Tempst P, Sabatini DM. G beta L, a positive regulator of the rapamycin-sensitive pathway required for the nutrient-sensitive interaction between raptor and mTOR. Mol Cell 11: 895-904, 2003.

20. Kolditz C, Borthaire M, Richard N, Corraze G, Panserat S, Vachot C, Lefevre F, Médale F. Liver and muscle metabolic changes induced by dietary energy content and genetic selection in rainbow trout (Oncorhynchus mykiss). Am J Physiol Regul Integr Comp Physiol 294: R1154R1164, 2008.

21. Kolditz CI, Paboeuf G, Borthaire M, Esquerre D, SanCristobal M, Lefevre F, Médale F. Changes induced by dietary energy intake and divergent selection for muscle fat content in rainbow trout (Oncorhynchus mykiss), assessed by transcriptome and proteome analysis of the liver. BMC Genomics 9: 506, 2008.

22. Leder EH, Silverstein JT. The pro-opiomelanocortin genes in rainbow trout (Oncorhynchus mykiss): duplications, splice variants, and differential expression. J Endocrinol 188: 355-363, 2006.

22a.Legate NJ, Bonen A, Moon TW. Glucose tolerance and peripheral glucose utilization in rainbow trout (Oncorhynchus mykiss), American eel (Anguilla rostrata), and black bullhead catfish (Ameiurus melas). Gen Comp Endocrinol 122: 48-59, 2001.

23. Macqueen DJ, Johnston IA. An update on MyoD evolution in teleosts and a proposed consensus nomenclature to accommodate the tetraploidization of different vertebrate genomes. PLoS One 3: e1567, 2008.

24. Marshall DM. Breed differences and genetic parameters for body composition traits in beef cattle. J Anim Sci 72: 2745-2755, 1994.

24a.Moon TW. Glucose intolerance in teleost fish: fact or fiction? Comp Biochem Physiol B 129: 243-249, 2001.

25. Navarro I, Leibush B, Moon TW, Plisetskaya EM, Banos N, Mendez E, Planas JV, Gutierrez J. Insulin, insulin-like growth factor-I (IGF-I) and glucagon: the evolution of their receptors. Comp Biochem Physiol B 122: 137-153, 1999.

26. Olsvik PA, Lie KK, Jordal AE, Nilsen TO, Hordvik I. Evaluation of potential reference genes in real-time RT-PCR studies of Atlantic salmon. BMC Mol Biol 6: 21, 2005. 
26a.Palmer TN, Ryman BE. Studies on oral glucose intolerance in fish. J Fish Biol 4: 311-319, 1972.

27. Panserat S, Capilla E, Gutierrez J, Frappart PO, Vachot C, PlagnesJuan E, Aguirre P, Breque J, Kaushik S. Glucokinase is highly induced and glucose-6-phosphatase poorly repressed in liver of rainbow trout (Oncorhynchus mykiss) by a single meal with glucose. Comp Biochem Physiol B 128: 275-283, 2001.

28. Panserat S, Médale F, Breque J, Plagnes-Juan E, Kaushik S. Lack of significant long-term effect of dietary carbohydrates on hepatic glucose6-phosphatase expression in rainbow trout (Oncorhynchus mykiss). J Nutr Biochem 11: 22-29, 2000.

29. Panserat S, Plagnes-Juan E, Breque J, Kaushik S. Hepatic phosphoenolpyruvate carboxykinase gene expression is not repressed by dietary carbohydrates in rainbow trout (Oncorhynchus mykiss). J Exp Biol 204: 359-365, 2001.

30. Park EA, Mynatt RL, Cook GA, Kashfi K. Insulin regulates enzyme activity, malonyl-CoA sensitivity and mRNA abundance of hepatic carnitine palmitoyltransferase-I. Biochem J 310: 853-858, 1995.

31. Parrizas M, Banos N, Baro J, Planas J, Gutierrez J. Up-regulation of insulin binding in fish skeletal muscle by high insulin levels. Regul Pept 53: 211-222, 1994.

32. Parrizas M, Planas J, Plisetskaya EM, Gutierrez J. Insulin binding and receptor tyrosine kinase activity in skeletal muscle of carnivorous and omnivorous fish. Am J Physiol Regul Integr Comp Physiol 266: R1944R1950, 1994.

33. Pfaffl MW. A new mathematical model for relative quantification in real-time RT-PCR. Nucleic Acids Res 29: e45, 2001.

34. Plagnes-Juan E, Lansard M, Seiliez I, Médale F, Corraze G, Kaushik S, Panserat S, Skiba-Cassy S. Insulin regulates the expression of several metabolism-related genes in the liver and primary hepatocytes of rainbow trout (Oncorhynchus mykiss). J Exp Biol 211: 2510-2518, 2008.

35. Porstmann T, Santos CR, Griffiths B, Cully M, Wu M, Leevers S, Griffiths JR, Chung YL, Schulze A. SREBP activity is regulated by mTORC1 and contributes to Akt-dependent cell growth. Cell Metab 8: 224-236, 2008.

36. Quillet E, Le Guillou S, Aubin J, Fauconneau B. Two-way selection for muscle lipid content in pan-size rainbow trout (Oncorhynchus mykiss). Aquaculture 245: 49-61, 2005.

37. Seiliez I, Gabillard JC, Skiba-Cassy S, Garcia-Serrana D, Gutierrez J, Kaushik S, Panserat S, Tesseraud S, Castillo J, Ammendrup-Johnsen
I, Codina M, Navarro I. An in vivo and in vitro assessment of TOR signaling cascade in rainbow trout (Oncorhynchus mykiss). Am J Physiol Regul Integr Comp Physiol 295: R329-R335, 2008.

38. Sellier P. Genetics of meat and carcass traits. In: The Genetics of the Pig. Wallingford, UK: CAB International, 1998.

39. Shimomura I, Shimano H, Horton JD, Goldstein JL, Brown MS. Differential expression of exons 1a and 1c in mRNAs for sterol regulatory element binding protein-1 in human and mouse organs and cultured cells. J Clin Invest 99: 838-845, 1997.

40. Smith S, Witkowski A, Joshi AK. Structural and functional organization of the animal fatty acid synthase. Prog Lipid Res 42: 289-317, 2003.

41. Snell K. Enzymes of serine metabolism in normal, developing and neoplastic rat tissues. Adv Enzyme Regul 22: 325-400, 1984.

42. Srivastava AK, Pandey SK. Potential mechanism(s) involved in the regulation of glycogen synthesis by insulin. Mol Cell Biochem 182: 135-141, 1998.

43. Sul HS, Latasa MJ, Moon Y, Kim KH. Regulation of the fatty acid synthase promoter by insulin. J Nutr 130: 315S-320S, 2000.

44. Taniguchi CM, Emanuelli B, Kahn CR. Critical nodes in signalling pathways: insights into insulin action. Nat Rev Mol Cell Biol 7: 85-96, 2006.

45. Towle HC, Kaytor EN, Shih H. Regulation of the expression of lipogenic enzyme genes by carbohydrate. Annu Rev Nutr 17: 405-433, 1997.

46. Tranulis MA, Christophersen B, Blom AK, Borrebaek B. Glucose dehydrogenase, glucose-6-phosphate dehydrogenase and hexokinase in liver of rainbow trout (Salmo gairdneri). Effects of starvation and temperature variations. Comp Biochem Physiol B 99: 687-691, 1991.

47. Tremblay F, Lavigne C, Jacques H, Marette A. Role of dietary proteins and amino acids in the pathogenesis of insulin resistance. Annu Rev Nutr 27: 293-310, 2007.

48. Wilson RP. Utilization of dietary carbohydrate by fish. Aquaculture 124: 67-80, 1994.

49. Wood JD, Enser M, Fisher AV, Nute GR, Sheard PR, Richardson RI, Hughes SI, Whittington FM. Fat deposition, fatty acid composition and meat quality: a review. Meat Sci 78: 343-358, 2008.

50. World Health Organization. Obesity and Overweight (WHO Fact Sheet No. 311). Geneva: WHO, 2006.

51. Wullschleger S, Loewith R, Hall MN. TOR signaling in growth and metabolism. Cell 124: 471-484, 2006. 